\title{
PROSPECTIVE STUDY OF EFFICACY OF LOCAL INFILTRATION ANALGESIA AND EPIDURAL ANALGESIA IN PATIENTS UNDERGOING TOTAL KNEE REPLACEMENTS
}

\author{
Manjunath Y. Hanjagi1, Prasad Varkey², Prakash V3 \\ ${ }^{1}$ Senior Resident, Department of Orthopaedics, WIMS Medical College and Hospital, Wayanad, Kerala. \\ ${ }^{2}$ Professor and HOD, Department of Orthopaedics, St. James Hospital, Chalakudy, Kerala. \\ ${ }^{3}$ Professor, Department of Orthopaedics, St. James Hospital, Chalakudy, Kerala.
}

\section{ABSTRACT}

\section{BACKGROUND}

Aims- Multiple studies have been done regarding post-operative analgesia after knee surgeries including intravenous opioids, epidural analgesia and nerve blocks. Hence, we compared the efficacy of Local Infiltration Analgesia (LIA) technique over Epidural Analgesia (EA) technique in patients undergoing TKR surgeries.

\section{MATERIALS AND METHODS}

72 patients of either sex, aged > 50 years, belonging to ASA I to III, posted for unilateral TKR for varus deformity were randomised into two groups. Patients in Group 1 received LIA and Group 2 EA. Parameters assessed were: Pain on VAS scale, Range of Movements (ROM), ambulation with support, patient satisfaction at 6 hrs., 24 hrs., 48 hrs., 72 hrs. and 96 hrs. Post-operatively.

\section{RESULTS}

Statistical analysis of the univariate and multivariate factors was performed using paired ' $t$ ', Chi-square test, Fisher's test as applicable. The pain was significantly more in LIA group than in EA group at 6 hrs., 24 hrs., 48 hrs., 72 hrs. and 96 hrs. intervals. The ROM was significantly observed more in LIA group than in EA group at 48 hrs. and 72 hrs. However, there was no significant difference at $96 \mathrm{hrs}$. between both groups. Ambulation with support was possible only in LIA group. Rescue analgesia was needed only in LIA group (13.9\% vs 0\%). Patients of EA group were more satisfied at the end of 4 days (86.1\% vs $69.4 \%)$.

\section{CONCLUSION}

Local infiltration analgesia provides simple, safe comparable analgesic efficacy and earlier ambulation than epidural analgesia post-operatively after total knee replacement surgery.

\section{KEYWORDS}

Total Knee Replacement, Local Infiltration Analgesia, Epidural Analgesia, Ropivacaine, Ketorolac, Adrenaline.

HOW TO CITE THIS ARTICLE: Hanjagi MY, Varkey P, Prakash V. Prospective study of efficacy of local infiltration analgesia and epidural analgesia in patients undergoing total knee replacements. J. Evolution Med. Dent. Sci. 2017;6(41):3214-3218, DOI: $10.14260 /$ Jemds/2017/696

\section{BACKGROUND}

Total Knee Replacement (TKR) is associated with moderateto-severe post-operative pain.[1,2] Multiple techniques of postoperative pain control have been used after knee surgeries including intravenous opioids, Epidural Analgesia (EA) and femoral nerve block. Parenteral opioids contribute to increased morbidity, hospital costs and patients may be at significant risk for opioid related adverse effects. ${ }^{[3-5]}$ Femoral block and oral medication is also commonly practised in orthopaedic departments. Each technique offers several side effects ${ }^{[6,7]}$ and therefore the search for other methods continues. The most common method used for pain relief is epidural analgesia, ${ }^{[8]}$ but it has several major negative side effects.

Multiple studies have documented the efficacy of Local Infiltration Analgesia (LIA) for TKR.[9,10] Many authors have

Financial or Other, Competing Interest: None.

Submission 28-03-2017, Peer Review 08-05-2017,

Acceptance 15-05-2017, Published 22-05-2017.

Corresponding Author:

Dr. Manjunath Y. Hanjagi,

C/o. A. S. Taradi,

H. No. 35, Prakruti Colony,

Girigaonkar Layout, Solapur Road,

Vijayapur-586103, Karnataka, India.

E-mail:drmanjunathyh@gmail.com

DOI: $10.14260 /$ jemds $/ 2017 / 696$ described methods using bupivacaine, ropivacaine or bupivacaine and morphine as either a single intra-articular injection or a continuous intra-articular infusion.[11-15] It significantly improves post-operative pain relief and may even reduce opioid consumption after TKR.[10,11,16-18] Placement of an intra-articular catheter allows prolonged site specific regional analgesia. This may be beneficial since studies have shown that the duration of analgesic effect for local infiltration is typically $8-12$ hrs. ${ }^{[11,18]}$ and possibly as long as $24 \mathrm{hrs.[17,19]}$

Hence, we aimed to compare the efficacy of LIA and EA using ropivacaine as local anaesthetic, ketorolac and adrenaline as adjuvant in patients undergoing unilateral total knee replacement for varus deformity with respect to postoperative pain relief (first 3 - 4 days), range of movement, ambulation, requirement of rescue analgesia and patient satisfaction.

\section{MATERIALS AND METHODS}

This prospective randomised study was conducted after obtaining approval from the Institutional Review Board. This prospective randomised study was carried out in patients undergoing unilateral TKR for varus deformity at our Institution from August 2012 to March 2014. Patients of either sex aged $>50$ years, belonging to American Society of Anaesthesiologists (ASA) I to III were included in the study. Patients who refused to give consent with significant 
systemic diseases, coagulation disorders, contraindications for EA and those patients with valgus knee were excluded from the study. Procedure was explained to the patients and written informed consent was obtained.

Patients were randomly allocated by paper envelop method into two groups of thirty six each. Patients in Group 1 received LIA and Group 2 received EA. The sample size was estimated based on a pilot study carried out in 10 patients, where it was found that mean VAS scores at 6 hours for the LIA group and the EA group were 2.3 and 1.9 respectively with Standard Deviation (SD) of 0.79. Based on these figures with alpha error $=0.05$, power of study $=0.85$ and using

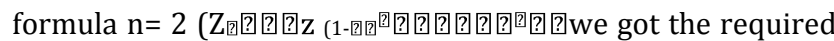
sample size of 72 cases. In our Institution during the study period, only 80 to 100 cases satisfying the inclusion criteria were expected. So all the cases satisfying the inclusion criteria were included in the study till the required sample size 72 cases were enrolled. 72 covers were prepared containing a sheet marked as LIA group in 36 covers and EA group in 36 covers. The patients were asked to pick a cover and were included in groups as per the entry in the sheet in the cover picked up. No pre-emptive analgesia was given and TKR was performed using standard techniques. All patients were operated by single surgeon.

Group 1 patients received LIA mixture containing $300 \mathrm{mg}$ ropivacaine $(250 \mathrm{mg}$ in patients less than $55 \mathrm{~kg}$ ), $30 \mathrm{mg}$ of ketorolac, $500 \mu \mathrm{g}$ of epinephrine diluted to $130-150 \mathrm{~mL}$ (Based on weight of patients) and injected over a period of 45 - 60 minutes as follows: LIA mixture of $30-50 \mathrm{~mL}$ was first injected into posterior capsule of knee joint after making bone cuts followed by another injection of $35-50 \mathrm{~mL}$ into the deep tissues around medial and lateral collateral ligaments after fixation of components and tourniquet release (Figure 1). The last infiltration of $35-50 \mathrm{~mL}$ was into the subcutaneous tissue and adjoining anteromedial/ anterolateral capsule of knee joint.

Before wound closure, a 19-G catheter was placed medially on raw bone medial to femoral component, inserted using Tuohy needle through vastus medialis obliquous and exiting subcutaneously away from incision, approximately 3 inches away from joint and fixed to skin. The catheter was fitted with an antibacterial filter and packed in a separate sterile dressing. At 20 - 24 hrs. post-operatively, the surgical field was reinjected with approximately $20 \mathrm{~mL}$ of LIA mixture through the catheter and the catheter removed.

Group 2 patients were put on continuous EA pump (Fitted with antibacterial filter) containing $2000 \mathrm{mg}$ of ropivacaine, $400 \mu \mathrm{g}$ of fentanyl at the rate of $5 \mathrm{~mL} / \mathrm{hr}(600$ $\mathrm{mg}$ ropivacaine and $80 \mu \mathrm{g}$ of fentanyl/day). Epidural pump was removed on $4^{\text {th }}$ post-operative day at the nadir of action of low molecular weight heparin.

Standard post-operative protocols were followed for all patients. Post-operatively, all patients were given a combination of trypsin-chymotrypsin $10 \mathrm{mg}$ thrice daily, omeprazole $20 \mathrm{mg}$ once daily for first 5 days. All patients received low molecular weight heparin for 1 week and started 24 hrs. post-operatively.

Parameters assessed were: Pain on Visual Analogue Scale (VAS), Range of Movements (ROM) and ambulation with support (knee brace and walker) at 6 hrs., 24 hrs., 48 hrs., 72 hrs. and $96 \mathrm{hrs}$. The need for rescue analgesia (opioids) and overall patient satisfaction was also assessed. VAS is a most common method for measuring pain and pain relief in clinical practice. $1-2=$ no pain, $3-4=$ mild pain, $5-6=$ moderate pain, $7-8=$ severe pain and $9-10=$ intolerable pain.

The information collected regarding all the selected cases were recorded in a master chart. Data analysis was done with the help of computer using Epidemiological Information Package (EPI 2010) developed by Centre for Disease Control, Atlanta. Using this software range, frequencies, percentages, means, standard deviations, Chi-square and ' $P$ ' values were calculated. Paired ' $t$ ' test was used to test the significance of difference between quantitative variables and Fisher's test, Chi-square tests for qualitative variables. A ' $P$ ' value less than 0.05 is taken to denote significant relationship.

\section{RESULTS}

Demographic profiles were evenly distributed between both the groups with respect to age, sex and side of operation (Table 1). Pain scores were recorded for the first 4 postoperative days. There was a significant difference in average pain score in the LIA group compared to EA group. VAS scores on post-operative day 1, 2, 3, 4 in both the groups were (2.1 vs 1.6$),(1.9$ vs 1.2 ), ( 1.3 vs 0.8$)$, ( 0.9 vs 0.6 ) respectively (Table 2). The ROM was more after 48 and 72 hrs. in EA group compared to LIA group and was statistically significant $(P=0.0071,0.0298)$ respectively. However, at 96 hours, ROM was found statistically insignificant $(P=0.0686)$. Ambulation with support (knee brace and walker) was possible only in LIA group. Almost all the patients in LIA group were ambulated by $96 \mathrm{hrs}$. Ambulation was possible for $8.3 \%, 44.4 \%, 72.2 \%, 86.1 \%$ patients at $24 \mathrm{hrs} ., 48 \mathrm{hrs} ., 72$ hrs. and 96 hrs. respectively. Ambulation in EA group was not possible till the end of 96 hrs. (Figure 2) and was statistically significant. Rescue analgesia was needed in $13.9 \%$ patients of LIA group. None of the patients in EA group required rescue analgesia and this was statistically significant (Figure 3) $(P$ value $=0.0269$ ). More number of patients in EA group were fully satisfied at the end of 4 days compared to LIA group (86.1\% vs $69.4 \%$ ). In LIA group $16.7 \%$ of patients were poorly satisfied as compared to nil patients in EA group. Rest of the patients in both groups were fairly satisfied and was found statistically significant (Figure 4).

\begin{tabular}{|c|c|c|c|}
\hline $\begin{array}{c}\text { Demographic } \\
\text { Profile }\end{array}$ & $\begin{array}{c}\text { LIA Group } \\
\text { Mean/SD }\end{array}$ & $\begin{array}{c}\text { Epidural Group } \\
\text { Mean/SD }\end{array}$ & $\boldsymbol{P}$ value \\
\hline $\begin{array}{c}\text { Age group in } \\
\text { years }\end{array}$ & $66.8 / 7.9$ & $65.1 / 9.3$ & 0.4131 \\
\hline Sex M/F (n) & $2 / 34$ & $4 / 32$ & 0.3369 \\
\hline $\begin{array}{c}\text { Side Left/ } \\
\text { Right (n) }\end{array}$ & $18 / 18$ & $16 / 20$ & 0.4068 \\
\hline
\end{tabular}

Table 1. Comparison of Demographic Profile between Two Groups. SD-Standard Deviation

\begin{tabular}{|c|c|c|c|c|c|}
\hline $\begin{array}{c}\text { Pain Score } \\
\text { (VAS) at }\end{array}$ & $\begin{array}{c}\text { LIA } \\
\text { Group }\end{array}$ & \multicolumn{2}{c|}{$\begin{array}{c}\text { Epidural } \\
\text { Group }\end{array}$} & \multirow{2}{*}{ P value } \\
\hline & Mean & SD & Mean & SD & \\
\hline 6 hours & 2.47 & 0.77 & 1.97 & 0.65 & 0.0042 \\
\hline 24 hours & 2.14 & 0.8 & 1.61 & 0.64 & 0.0029 \\
\hline 48 hours & 1.92 & 0.6 & 1.22 & 0.87 & 0.0002 \\
\hline 72 hours & 1.31 & 0.71 & 0.81 & 0.82 & 0.0073 \\
\hline 96 hours & 0.94 & 0.63 & 0.61 & 0.73 & 0.0414 \\
\hline \multicolumn{6}{|c|}{ Table 2. Comparison of Pain Score (VAS) at } \\
various Time Intervals \\
\hline
\end{tabular}




\begin{tabular}{|c|c|c|c|c|c|}
\hline \multirow{2}{*}{$\begin{array}{c}\text { ROM in } \\
\text { Degrees } \\
\text { At }\end{array}$} & \multicolumn{2}{|c|}{ LIA Group } & \multicolumn{2}{c|}{ Epidural Group } & \multirow{2}{*}{ v value } \\
\cline { 2 - 5 } & Mean & SD & Mean & SD & \\
\hline 6 hours & 21.39 & 7.62 & 20.28 & 6.96 & 0.5204 \\
\hline 24 hours & 44.17 & 10.79 & 49.72 & 13.62 & 0.0592 \\
\hline 48 hours & 49.72 & 10.55 & 58.61 & 16.06 & 0.0071 \\
\hline 72 hours & 55.56 & 11.82 & 63.33 & 17.4 & 0.0298 \\
\hline 96 hours & 61.11 & 13.04 & 67.5 & 16.1 & 0.0686 \\
\hline Table 3. Comparison of ROM at various Time Intervals \\
\hline
\end{tabular}

\begin{tabular}{|c|c|c|c|c|}
\hline Authors & (n) & Group 1-LIA & Group 2 & Observation \\
\hline $\begin{array}{l}\text { Kerr } \\
\text { DR, } \\
\text { et } \mathrm{al}^{10}\end{array}$ & 325 & & $\begin{array}{l}\text { Epidural } \\
\text { Analgesia }\end{array}$ & $\begin{array}{c}\text { In LIA group pain } \\
\text { control was } \\
\text { satisfactory, no } \\
\text { morphine was } \\
\text { required in two-thirds } \\
\text { of patients }\end{array}$ \\
\hline $\begin{array}{l}\text { Bush } \\
\text { CA, } \\
\text { et al }{ }^{16}\end{array}$ & 64 & \begin{tabular}{|l|} 
Peri-articular \\
injection \\
containing \\
ropivacaine, \\
ketorolac, \\
epimorphine \\
and \\
epinephrine \\
\end{tabular} & & $\begin{array}{c}\text { Peri-articular } \\
\text { analgesia significantly } \\
\text { reduce the } \\
\text { requirement for } \\
\text { rescue analgesia and } \\
\text { improve patient } \\
\text { satisfaction with no } \\
\text { apparent risks } \\
\end{array}$ \\
\hline $\begin{array}{c}\text { Anderso } \\
\mathrm{n} \mathrm{KV} \text {, et } \\
\text { al }\end{array}$ & 40 & \begin{tabular}{|} 
Wound \\
infiltration \\
with intra- \\
articular \\
infusion \\
using \\
ropivacaine \\
and ketorolac
\end{tabular} & $\begin{array}{c}\text { Epidural } \\
\text { Analgesia }\end{array}$ & $\begin{array}{c}\text { Peri-articular and } \\
\text { intra-articular } \\
\text { analgesia provided } \\
\text { superior pain relief } \\
\text { and reduced morphine } \\
\text { consumption } \\
\text { compared with } \\
\text { continuous epidural } \\
\text { infusion }\end{array}$ \\
\hline $\begin{array}{c}\text { Spreng } \\
\text { UJ, } \\
\text { et al }\end{array}$ & 102 & \begin{tabular}{|} 
Ropivacaine \\
$150 \mathrm{mg}$ \\
adrenaline \\
$0.5 \mathrm{mg}$
\end{tabular} & $\begin{array}{c}\text { Epidural } \\
\text { Analgesia }\end{array}$ & $\begin{array}{l}\text { LIA reduced opioid } \\
\text { consumption, } \\
\text { facilitated faster } \\
\text { mobilisation and early } \\
\text { discharge from } \\
\text { hospital, but verbal } \\
\text { pain scores were } \\
\text { lower in EDA group }\end{array}$ \\
\hline $\begin{array}{c}\text { Martin } \\
\text { Thorsell, } \\
\text { et al }\end{array}$ & 85 & $\begin{array}{l}\text { Ropivacaine } \\
300 \mathrm{mg}, \\
\text { adrenaline } \\
0.5 \mathrm{mg}\end{array}$ & $\begin{array}{c}\text { Epidural } \\
\text { Analgesia }\end{array}$ & $\begin{array}{l}\text { LIA offers equal pain } \\
\text { relief as that of } \\
\text { epidural anaesthesia, } \\
\text { but also faster } \\
\text { mobilisation and more } \\
\text { patient satisfaction } \\
\text { than epidural } \\
\text { anaesthesia }\end{array}$ \\
\hline $\begin{array}{c}\text { Essving } \\
\mathrm{P} \text {, et al }\end{array}$ & 40 & \begin{tabular}{|}
$200 \mathrm{mg}$ \\
ropivacaine, \\
$30 \mathrm{mg}$ \\
ketorolac and \\
$0.5 \mathrm{mg}$ \\
epinephrine
\end{tabular} & $\begin{array}{c}\text { Saline } \\
\text { Injected }\end{array}$ & $\begin{array}{c}\text { Excellent pain relief } \\
\text { and earlier discharge } \\
\text { in LIA group compared } \\
\text { to control group }\end{array}$ \\
\hline $\begin{array}{c}\text { B. } \\
\text { Garica- } \\
\text { Benitez } \\
\text { et al }\end{array}$ & 90 & & $\begin{array}{c}\text { Epidural } \\
\text { Analgesia }\end{array}$ & \begin{tabular}{|c} 
Peri-articular \\
infiltration with \\
analgesic cocktail \\
before incision closure \\
is a good treatment \\
option for post- \\
operative pain in TKR
\end{tabular} \\
\hline \multicolumn{5}{|c|}{$\begin{array}{l}\text { Table 4. Comparison of Present Study Results with Other } \\
\text { Studies }\end{array}$} \\
\hline
\end{tabular}

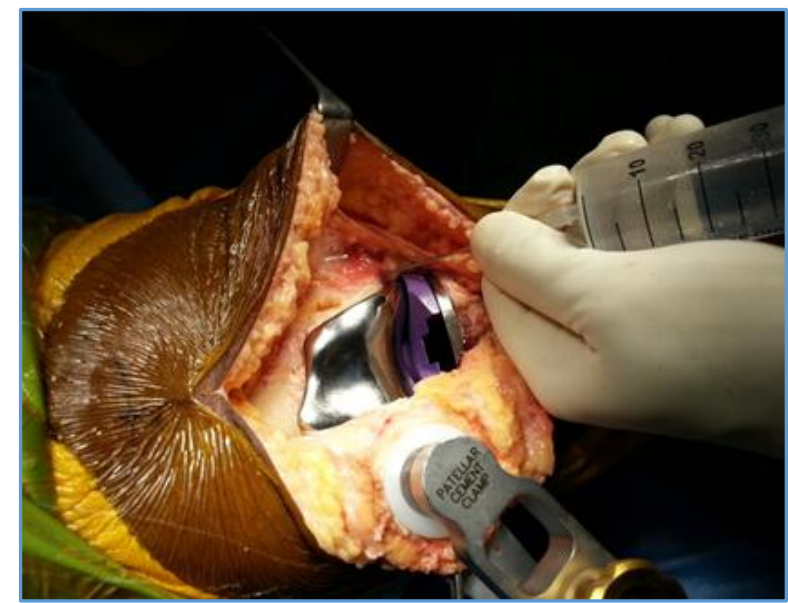

Figure 1. Local Infiltration Analgesia Injecting into Medial Collateral Ligament of Knee Joint

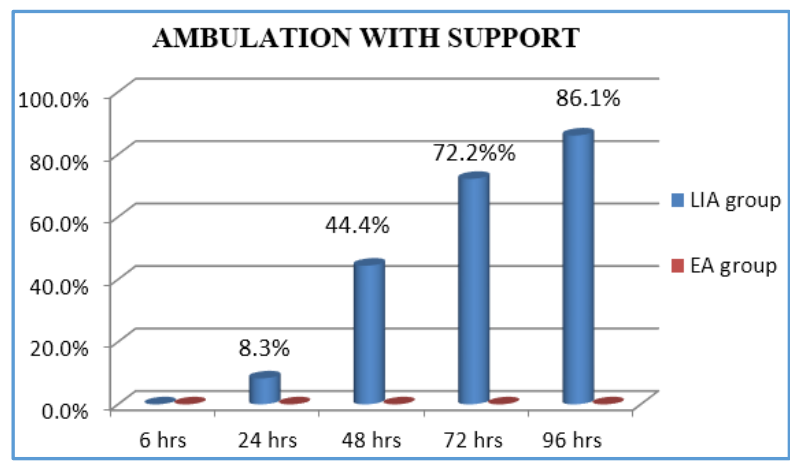

Figure 2. Comparison of Ambulation at various Time Intervals

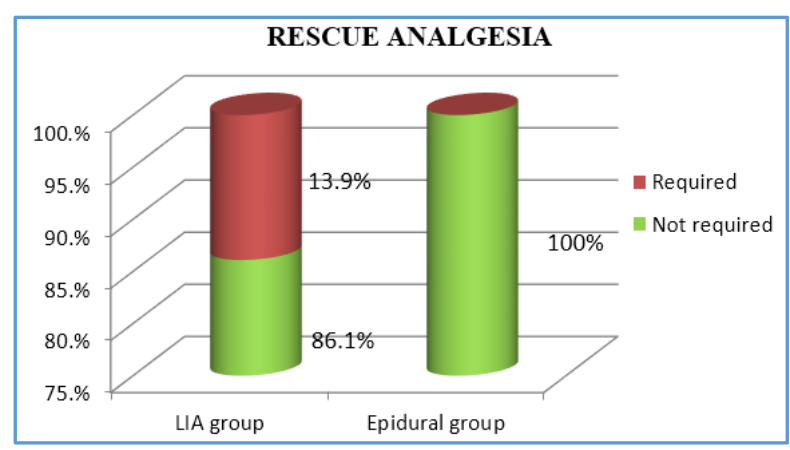

Figure 3. Comparison of Rescue Analgesia between Two Groups

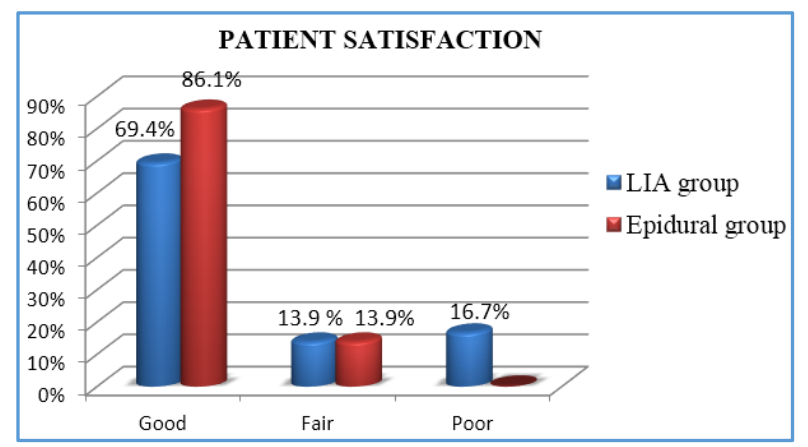

Figure 4. Comparison of Patient Satisfaction between Two Groups 


\section{DISCUSSION}

Post-operative pain control after TKR offers a clinical challenge. Pain contributes to immobility related complications, prolonged hospital stay and interferes with optimal post-operative knee rehabilitation. Arthrofibrosis and diminished range of movements are closely related to degree of post-operative pain.[20,21]

The most common method used is epidural analgesia that offers good pain relief,43 has several complications such as motor weakness, urinary retention and hypotonia. Even complications such as epidural haematoma, spinal infection have recently led to questioning of its routine use, specifically in older women.[22] Continuous epidural analgesia using pump has inherent disadvantages- hypotension, urinary retention. ${ }^{[23,24]}$ Epidural catheter complications, DVT, delayed ambulation, need to use anticoagulants, more expensive equipment and prolonged hospital stay.[10,25,26] LIA overcomes some of these disadvantages. It is cheaper, allows early mobilisation and ambulation, thereby obviating requirement of anticoagulants, preventing systemic complications and early discharge from hospital. It also decreases blood loss and need for rescue analgesia.[11] Multiple studies have been done with LIA by either using single shot injection intraoperatively, ${ }^{[11,16-18]}$ continuous intra-articular injection for 24 - 48 hrs. after surgery.[27-29] The benefits of the LIA technique are good post-operative pain control, fast mobilisation and early discharge from hospital.[27-32] It reduces opioid consumption post-operatively after total knee replacement.[2,5,17,18] It also decreases blood loss. ${ }^{[11]}$

Our analysis revealed that after TKR, EA group had significantly less intensity of pain than LIA group at $1-4^{\text {th }}$ post-operative day. Use of continuous epidural pump postoperatively had more beneficial effect on pain scores in EA group compared to LIA group.

The ROM was significantly more at $48 \mathrm{hrs}$. and $72 \mathrm{hrs}$. in epidural analgesia group than LIA group. However, there was no significant difference between both groups at the $4^{\text {th }}$ postoperative day. Ambulation with support was possible only in LIA group. Ambulation in epidural analgesia group was not possible by 96 hours. ${ }^{[30,33]}$ We found that the patients in the LIA group could get in and out of bed without personal assistance and could walk with walker support from $48 \mathrm{hrs}$. onwards. Hence, LIA can be a part of fast-track arthroplasty surgery. In present study blood loss was less in LIA group, but it was not calculated and proved statistically. Both group's patients were discharged after stitch removal on $11^{\text {th }}$ postoperative day. Rescue analgesia was required in $13.9 \%$ patients of LIA group, whereas none of the patients in epidural analgesia group required rescue analgesia. No postoperative complications like DVT, hypotension or urinary retention were observed in both the groups.

In EA group though patients were more satisfied with respect to pain, early ambulation was not possible in contrast to LIA group. However, range of movements were similar in both the groups at the end of $96 \mathrm{hrs}$.

\section{Limitations}

The study was limited to only 72 patients. Larger number of enrolled cases are required to assess the risk of infections associated with LIA-injection of high volumes of nonphysiological fluids both in interstitial spaces and intra- articularly through catheter. The study duration was limited to 96 hrs. post-operatively. Use intra-articular ketorolac, as adjuvant has negative effect on bone healing[34,35,36] and may increase the risk of endoprosthetic loosening.[2] Longer duration of study period is required to assess long-term complications like endoprosthetic loosening.

\section{CONCLUSION}

Local infiltration analgesia is a better alternative to epidural analgesia. In LIA group the advantages noted were early ambulation, lesser blood loss, less expensive, no urinary retention or hypotension. However, pain relief was more satisfactory in epidural analgesia group. In LIA group, rescue analgesia was not required in more than two-third patients and more than two-third patients were fully satisfied. More than two-third patients were ambulated with walker by 72 hrs., whereas none were ambulant by 96 hours in EA group.

\section{REFERENCES}

[1] Wang H, Boctor B, Verner J. The effect of single injection femoral nerve block on rehabilitation and length of hospital stay after total knee replacement. Reg Anesth Pain Med 2002;27(2):139-44.

[2] Axelsson K, Johanzon E, Essving P, et al. Postoperative extradural analgesia with morphine and ropivacaine. A double blind comparison between placebo and ropivacaine $10 \mathrm{mg} / \mathrm{h}$ or $16 \mathrm{mg} / \mathrm{h}$. Acta Anaesthesiol Scand 2005;49(8):1191-9.

[3] Wheeler M, Oderda GM, Ashburn MA, et al. Adverse events associated with postoperative opioid analgesia: a systematic review. J Pain 2002;3(3):159-80.

[4] Philip BK, Reese PR, Burch SP. The economic impact of opioids on postoperative pain management. J Clin Anesth 2002;14(5):354-64.

[5] Oderda GM, Evans RS, Lloyd J, et al. Cost of opioidrelated adverse drug events in surgical patients. J Pain Symptom Manage 2003;25(3):276-83.

[6] Choi PT, Bhandari M, Scott J, et al. Epidural analgesia for pain relief following hip or knee replacement. Cochrane Database Syst Rev 2003;(3):CD003071.

[7] Morin AM, Kratz CD, Eberhart LH, et al. Postoperative analgesia and functional recovery after total-knee replacement: comparison of a continuous posterior lumbar plexus (psoas compartment) block, a continuous femoral nerve block, and the combination of a continuous femoral and sciatic nerve block. Reg Anesth Pain Med 2005;30(5):434-45.

[8] Mahoney OM, Noble PC, Davidson J, et al. The effect of continuous epidural analgesia on postoperative pain, rehabilitation, and duration of hospitalization in total knee arthroplasty. Clin Orthop Relat Res 1990;(260):30-7.

[9] McNamee DA, Parks L, Milligan KR. Post-operative analgesia following total knee replacements: an evaluation of the addition of an obturator nerve block to combined femoral and sciatic nerve block. Acta Anaesthesiol Scand 2002;46(1):95-9.

[10] Kerr DR, Kohan L. Local infiltration analgesia: a technique for the control of acute postoperative pain after knee \& hip surgery: a case study of 325 patients. Acta Orthop 2008;79(2):174-83. 
[11] Lombardi AV, Berend KR, Mallory TH, et al. Soft tissue and intra-articular injection of bupivacaine, epinephrine, and morphine has a beneficial effect after total knee arthroplasty. Clin Orthop Relat Res 2004;(428):125-30.

[12] Browne C, Copp S, Reden L, et al. Bupivacaine bolus injection versus placebo for pain management following total knee arthroplasty. J Arthroplasty 2004;19(3):377-80.

[13] Mauerhan DR, Campbell M, Miller JS, et al. Intraarticular morphine and/or bupivacaine in the management of pain after total knee arthroplasty. J Arthroplasty 1997;12(5):546-52.

[14] Badner $\mathrm{NH}$, Bourne RB, Rorabeck $\mathrm{CH}$, et al. Intraarticular injection of bupivacaine in knee-replacement operations. Results of use for analgesia and for preemptive blockade. J Bone Joint Surg Am 1996;78(5):734-8.

[15] Nechleba J, Rogers V, Cortina G, et al. Continuous intraarticular infusion of bupivacaine for postoperative pain following total knee arthroplasty. J Knee Surg 2005;18(3):197-202.

[16] Bush CA, Shore BJ, Bhandari R, et al. Efficacy of periarticular multimodal drug injection in total knee arthroplasty. A randomized trial. J Bone Joint Surg Am 2006;88(5):959-63.

[17] Reilly KA, Beard DJ, Barker KL, et al. Efficacy of an accelerated recovery protocol for oxford unicompartmental knee arthroplasty - a randomised controlled trial. Knee 2005;12(5):351-7.

[18] Fu PL, Xiao J, Zhu YL, et al. Efficacy of a multimodal analgesia protocol in total knee arthroplasty: a randomized control trial. J Int Med Res 2010;38(4):1404-12.

[19] Koh IJ, Kang YG, Chang CB, et al. Additional pain relieving effect of intraoperative periarticular injections after simultaneous bilateral total knee arthroplasty: a randomized, controlled study. Knee Surg Sports Traumatol Arthrosc 2010;18(7):916-22.

[20] Ranawat CS, Ranawat AS, Mehta A. Total knee arthroplasty rehabilitation protocol: what makes the difference? J Arthroplasty 2003;18(3 Suppl 1):27-30.

[21] Singelyn FJ, Deyaert M, Joris D, et al. Effects of intravenous patient-controlled analgesia with morphine, continuous epidural analgesia, and continuous three-in-one block on postoperative pain and knee rehabilitation after unilateral total knee arthroplasty. Anesth Analg 1998;87(1):88-92.

[22] Moen V, Dahlgren N, Irestedt L. Severe neurological complications after central neuraxial blockade in Sweden 1990-1999. Anesthesiology 2004;101(4): 950-9.

[23] Imbelloni LE, Gouveia MA, Cordeiro JA. Continuous spinal anesthesia versus combined spinal epidural block for major orthopedic surgery: prospective randomized study. Sao Paulo Med J 2009;127(1):7-11.
[24] Campbell A, McCormick M, McKinlay K, et al. Epidural vs. lumbar plexus infusions following total knee arthroplasty: randomized controlled trial. Eur J Anaesthesiol 2008;25(6):502-7.

[25] Thorsell M, Holst P, Hyldal HC, et al. Pain control after total knee arthroplasty: a prospective study comparing local infiltration anesthesia and epidural anesthesia. Orthopedics 2010;33(2):75-80.

[26] Bianconi M, Ferraro L, Traina GC, et al. Pharmacokinetics and efficacy of ropivacaine continuous wound instillation after joint replacement surgery. Br J Anaesth 2003;91(6):830-5.

[27] Rasmuseen S, Kramhoft MU, Sperling KP, et al. Increased flexion and reduced hospital stay with continuous intraarticular morphine and ropivacaine after primary total knee replacement: open intervention study of efficacy and safety in 154 patients. Acta Orthop Scand 2004;75(5):606-9.

[28] Anderson KV, Bak M, Christensen BV, et al. A randomized control trial comparing local infiltration analgesia with epidural infusion for total knee arthroplasty. Acta Orthop 2010;81(5):606-10.

[29] Liu W, Cong R, Li X, et al. Reduced opioid consumption and improved early rehabilitation with local and intra articular cocktail analgesic injection in total hip arthroplasty: a randomized controlled clinical trial. Pain Med 2011;12(3):387-93.

[30] Spreng UJ, Dahl V, Hjall A, et al. High-volume local infiltration analgesia combined with intravenous or local ketorolac plus morphine compared with epidural analgesia after total knee arthroplasty. Br J Anaesth 2010;105(5):675-82.

[31] Carli F, Clemente A, Asenjo JF, et al. Analgesia and functional outcome after total knee arthroplasty: periarticular infiltration verses continuous femoral nerve block. Br J Anaesth 2010;105(2):185-95.

[32] Andersen LO, Gaarn-Larsen L, Kristensen BB, et al. Analgesic efficacy of local anaesthetic wound administration in knee arthroplasty: volume verses concentration. Anaesthesia 2010;65(10):984-90.

[33] Essving P, Axelsson K, Kjellberg J, et al. Reduced hospital stay, morphine consumption and pain intensity with local infiltration analgesia after unicompartmental knee arthroplasty. Acta Orthopaedica 2009;80(2):213-9.

[34] Garcia- Benitez B, Coronado-Hijon V, Villa-Gil M, et al. Randomised prospective study of three methods of post-operative analgesia in total knee replacement. J Bone Joint Surg Br 2009.

[35] Boezaart AP. Perineural infusion of local anesthetics. Anesthesiology 2006;104(4):872-80.

[36] Liu S, Carpenter RL, Neal JM. Epidural anesthesia and analgesia. Their role in postoperative outcome. Anesthesiology 1995;82(6):1474-506. 